\title{
General practice recommendations for the topical treatment of psoriasis: a modified-Delphi approach
}

\section{Diamant Thaçi ${ }^{1}$, Pablo de la Cueva ${ }^{2}$, Andrew E Pink ${ }^{3}$, Ahmad Jalilii, Siegfried Segaert ${ }^{5}$, Kasper F Hjuler ${ }^{6}$, Piergiacomo Calzavara-Pinton ${ }^{7 *}$}

${ }^{1}$ Institute and Comprehensive Center for Inflammation Medicine, University of Lübeck, Lübeck, Germany; ${ }^{2}$ Department of Dermatology, University Hospital Infanta Leonor de Madrid, Madrid, Spain; ${ }^{3}$ St John's Institute of Dermatology, Guy's and St Thomas' NHS Foundation Trust, London, UK; ${ }^{4}$ Department of Dermatology, Bürgenstock Medical Center, Obbürgen, Switzerland; ${ }^{5}$ Consultant Dermatologist, Bonheiden, Belgium; 'Department of Dermatology, Aarhus University Hospital, Aarhus, Denmark; ${ }^{7}$ Department of Dermatology, University of Brescia, Brescia, Italy

\begin{abstract}
Background: Although GPs are usually the first port of call for patients with psoriasis, there is a lack of consistent and up-to-date clinical recommendations for interventions for patients with mild-tomoderate disease.

Aim: To provide practical recommendations for GPs to optimise psoriasis treatment with topical therapies in four key areas: patient identification; treatment decision making with topical theory; topical treatment outcomes; and optimising patient adherence.

Design \& setting: A consensus-seeking programme (modified-Delphi approach) was undertaken to assess the literature and develop recommendations for GPs, based on evidence and expert opinion.

Method: Three dermatologists compiled 47 questions that were subsequently ranked and refined according to clinical relevance or importance using an online survey. Thereafter, 19 dermatologists from different European countries developed statements and clinical recommendations for the top seven ranked topical treatment and GP-relevant questions based on literature research and clinical experience. The final recommendations were based on $100 \%$ agreement among a final panel of seven experts.
\end{abstract}

Results: The clinical effectiveness, fast onset of action, tolerability, cosmetic acceptability, and practicability of topical therapy, in addition to good physician-patient communication, are important for optimising patient adherence and maximising efficacy. Topical treatments combining corticosteroids and vitamin $D$ analogues (administered as fixed combination) are well-established first-line treatments in mild-to-moderate psoriasis.

Conclusion: Simple but detailed practical guidance is provided, which is formed from evidence and expert clinical recommendations, to assist GPs with the optimal use of topical agents based on efficacy, tolerability, disease severity, site of psoriasis, patient lifestyle and preferences, and intended duration of treatment.

\section{How this fits in}

Topical treatments are indicated as first-line treatment options for patients with mild-to-moderate psoriasis. In order to maximise patient outcomes to topical treatments, tailored up-to-date guidance 
Table 1 Final questions

1. Which patients are candidates for topical psoriasis treatment?

2. What factors inform the selection of one topical treatment over another for mild-to-moderate psoriasis?

3. What outcomes should a physician or patient expect from topical treatment and within what timeframe?

4. How long should topical treatments be used for?

5. What are the drivers of treatment switching?

6. What features of a topical treatment maximise adherence?

7. What simple instructions can be shared with patients regarding the use of topical treatments to maximise efficacy and adherence?

for GPs is needed. This guidance, based on evidence and expert clinical recommendations, provides practical recommendations for GPs, with the aim of optimising use of topical treatments and improving patient outcomes. Topics covered include: patient identification; treatment decision making with topical therapy; topical treatment outcomes; and optimising patient adherence.

\section{Introduction}

Psoriasis is a chronic, immune-mediated, inflammatory skin disease, which affects around $2 \%$ of the Western population. ${ }^{1,2}$ The most common form, psoriasis vulgaris/plaque psoriasis, accounts for the majority of cases and is defined by recurrent scaly, itchy, erythematous plaques that usually affect the elbows, knees, scalp, sacral region, and intertriginous areas. ${ }^{3,4}$ Patients with psoriasis experience varying degrees of severity and disability, and the socioeconomic impact of psoriasis can cause decade-long impairments in quality of life $(\mathrm{QoL}) .^{3,5}$ In many countries, most patients with mild-tomoderate psoriasis are managed in primary care by GPs. ${ }^{6}$

Approximately $80 \%$ of patients with psoriasis have localised disease, which can be treated with topical therapies. ${ }^{7}$ Currently approved topical treatments include corticosteroids, vitamin D analogues, combination corticosteroid and vitamin D, vitamin A derivatives (tazarotene), anthralin, and newer formulations of tar. ${ }^{7}$ Adherence rates to topical treatments are relatively low, varying from $50 \%-70 \%$, ${ }^{2,8}$ with rates even lower (40\%) for topical corticosteroids and in patients with severe psoriasis. ${ }^{8}$ Almost $50 \%$ of topical treatment prescriptions for psoriasis remain unfilled. ${ }^{9}$

While there are several guidelines available on the management of psoriasis, the majority of these focus on systemic treatments, and there is a lack of up-to-date practical recommendations specifically tailored for GPs regarding topical treatments and how they can help to maximise patient outcomes. ${ }^{10-13}$ This guidance seeks to provide clarity around, and support implementation of, treatment algorithms, and aid clinicians in optimising an individual's care. Clear guidance is provided in four key areas to support practical implementation: patient identification; treatment decision making with topical therapy; topical treatment outcomes; and optimising patient adherence. Guidance regarding the use of topical agents while transitioning to systemic treatments is also discussed.

Table 2 Summary of literature searches

\begin{tabular}{ll}
\hline Database searched & PubMed (MEDLINE) \\
\hline Date of search & April 2018 \\
\hline Limits & Languages: English \\
& Species: humans \\
& Publication date: last 5 years \\
\hline Manual searches & Abstracts: \\
& European Academy of Dermatology and Venereology \\
& meetings 2016 and 2017 \\
& American Academy of Dermatology meetings 2016, 2017, \\
& and 2018 \\
\hline Inclusion criteria & Systematic reviews, meta-analyses, clinical practice \\
& guidelines, and reports of clinical trials, randomised clinical \\
trials, cohort studies, registry analyses, and case series \\
\hline Exclusion criteria & Non-English \\
& Non-human \\
& References older than 5 years \\
References that are not focused on topical treatments
\end{tabular}




\section{Method}

This was a consensus-seeking programme using a modified-Delphi approach as outlined below. An expert group of seven dermatologists (DT, PC, AEP, AJ, SS, KFH, and PGC-P; the 'core group') from across Europe participated in a programme to devise recommendations for the use of topical treatments. With the exception of $\mathrm{KFH}$, the experts had originally been selected to participate in a LEO Pharma-funded international steering committee in which the need for this initiative was highlighted. KFH was contracted by LEO Pharma to support with the initiative. All of the experts were identified based on their extensive psoriasis clinical expertise. They were selected from different European countries in order to provide a comprehensive evaluation of possible local differences in topical therapeutic approaches to psoriasis. Supplementary Figure S1 provides an overview of the programme. The 'working group' (PB, PGC-P, and PC), nominated by the core group, identified 47 potentially relevant questions this initiative could seek to address. A survey to prioritise these questions and determine which were the most clinically important and relevant to address was shared with a wider group of expert dermatologists (selected by the core group based on dermatology expertise), and a final list of seven questions relating to topical treatment and relevant to GPs was generated (Table 1). The wider expert group included the authors of this manuscript and 12 additional practising dermatologists from 10 countries, thus providing a breadth of clinical experience from many healthcare systems.

The working group, supported by medical writers from Leading Edge Medical Communications, conducted literature searches (details of the literature searches are provided in Table 2 and search strings used for each question are provided in Supplementary Table S1) to address each question and the working group alone developed draft statements summarising the literature. Available evidence obtained for each literature statement was assigned a level of evidence, graded in line with the Oxford Centre for Evidence Based Medicine. ${ }^{14}$ Additionally, the working group addressed evidence gaps by providing practical clinical recommendations based on their clinical experience and expert opinion. A second survey of the wider expert group obtained feedback on the draft statements and recommendations. Responders were asked if they agreed with the draft summary statements and clinical recommendations, to rank the latter according to clinical importance, and to suggest any additional clinical recommendations. The final summary statements and clinical recommendations were then generated based on $100 \%$ agreement among the core group and are presented herein.

\section{Results}

Clinical recommendations are provided below for each of the questions. Summary statements regarding the rationale behind each of these, as well as additional tips, are provided in Supplementary Table S2.

\section{Patient identification and profile}

Question 1: Which patients are candidates for topical psoriasis treatment?

a. Topical treatment (selected according to specific body sites and the clinical phenotype of disease) is generally a first-line treatment approach in all patients treated by GPs.

b. Patients with moderate or severe disease receiving systemic therapies or phototherapy may benefit from concomitant topical therapies because residual disease can cause considerable impact on health-related quality of life (HROoL).

\section{Drivers of treatment decision}

Question 2: What factors inform the selection of one topical treatment over another for mild-to-moderate psoriasis?

a. Choice of topical agent should be based on the site (Table 3 and Table 4), extent and features of psoriasis, such as level of hyperkeratosis, redness, thickness, presence of inflammation, severity of itch, and pain.

b. Practical factors should be considered, for example, formulation (Table 3), and discussed with your patient to ensure suitability. 
Table 3 Advantages, limitations, and practical considerations of the most commonly used topical formulations for psoriasis

\begin{tabular}{|c|c|c|c|}
\hline Vehicle formulation & Advantages & Limitations & Typical use \\
\hline Ointment & $\begin{array}{l}\text { Occlusive effect, potentially } \\
\text { improves penetration and } \\
\text { efficacy. }{ }^{26} \text { Hydrating effect. } \\
\text { Simple formula, often } \\
\text { preservative-free. }\end{array}$ & $\begin{array}{l}\text { Greasiness as no } \\
\text { evaporation or } \\
\text { absorption. }{ }^{27} \\
\text { Can be time-consuming } \\
\text { and less cosmetically } \\
\text { appealing. }^{28}\end{array}$ & $\begin{array}{l}\text { Dry, thick, scaly plaques } \\
\text { for body. } \\
\text { Not for hair-bearing skin. }\end{array}$ \\
\hline Cream & $\begin{array}{l}\text { Less greasy, more spreadable } \\
\text { than ointment. } \\
\text { Some hydrating effect. } \\
\text { Cosmetically acceptable. }\end{array}$ & $\begin{array}{l}\text { Less occlusive effect, } \\
\text { decreased penetration and } \\
\text { efficacy compared with } \\
\text { ointment. }\end{array}$ & $\begin{array}{l}\text { All body areas. } \\
\text { Hair-bearing areas } \\
\text { including scalp with } \\
\text { correct application } \\
\text { technique. }\end{array}$ \\
\hline Gel; water- or lipid-based & $\begin{array}{l}\text { Easy application, easy to } \\
\text { spread. }^{27} \\
\text { Cosmetically acceptable. }\end{array}$ & $\begin{array}{l}\text { Minimal or no occlusion. } \\
\text { Minimal hydration. }\end{array}$ & $\begin{array}{l}\text { All body areas, especially } \\
\text { well-suited for hair- } \\
\text { bearing skin. }\end{array}$ \\
\hline $\begin{array}{l}\text { Aerosol foam; } \\
\text { hydroalcoholic or } \\
\text { emollient-based }\end{array}$ & $\begin{array}{l}\text { Easy application, easy to } \\
\text { spread. } \\
\text { Usually no preservatives. } \\
\text { Some skin hydration if } \\
\text { emollient-based. }{ }^{29} \\
\text { Cosmetically acceptable. }\end{array}$ & $\begin{array}{l}\text { Minimal occlusion } \\
\text { and hydrating effects } \\
\text { (hydroalcoholic). } \\
\text { Some greasiness if } \\
\text { emollient-based foam. } \\
\text { Risk of stinging, irritation, } \\
\text { and dryness if alcohol- } \\
\text { based. }{ }^{29}\end{array}$ & $\begin{array}{l}\text { All body areas, especially } \\
\text { hair-bearing areas (if not } \\
\text { emollient-based). }\end{array}$ \\
\hline Lotion & $\begin{array}{l}\text { Easy application, not greasy. } \\
\text { Cosmetically acceptable. } \\
\text { Cooling skin effect. }^{27}\end{array}$ & $\begin{array}{l}\text { No occlusive effect. } \\
\text { No or minimal hydration. }\end{array}$ & $\begin{array}{l}\text { Hair-bearing areas. } \\
\text { Not optimal for the } \\
\text { treatment of thick, scaly } \\
\text { plaques in other areas. }\end{array}$ \\
\hline $\begin{array}{l}\text { Solution; alcohol- or water- } \\
\text { based }\end{array}$ & $\begin{array}{l}\text { Easy to spread. } \\
\text { Not greasy. } \\
\text { No residue. } \\
\text { Cosmetically acceptable. }\end{array}$ & $\begin{array}{l}\text { Stinging, irritation, and } \\
\text { dryness if alcohol-based. } \\
\text { Needs to be shaken } \\
\text { (inhomogeneous solution). }\end{array}$ & $\begin{array}{l}\text { Hair-bearing areas. } \\
\text { Avoid alcoholic solutions } \\
\text { if they crack or excoriate } \\
\text { skin. }\end{array}$ \\
\hline Shampoo & $\begin{array}{l}\text { Developed for scalp use. } \\
\text { Not greasy. } \\
\text { Cosmetically acceptable. }\end{array}$ & $\begin{array}{l}\text { No occlusive or hydrating } \\
\text { effect. } \\
\text { Complex application } \\
\text { procedure. } \\
\text { Short contact time with } \\
\text { skin. }\end{array}$ & $\begin{array}{l}\text { Hair-bearing areas, } \\
\text { especially scalp with } \\
\text { dense hair growth. }\end{array}$ \\
\hline
\end{tabular}

Individual patient preferences, drug characteristics, and active pharmaceutical ingredient (API)-specific features have not been taken into account.

c. If prescribing corticosteroids, the right potency for the area affected should be chosen (see Table 4 for guidance).

d. There are systemic safety issues with use of potent corticosteroids on large skin areas that are more pronounced if the area is occluded.

e. Initial use of low-potency (for example, hydrocortisone cream 1\%) or underdosed topical corticosteroids should be avoided as treatment is unlikely to be successful and this could adversely affect adherence.

f. Special consideration needs to be given to certain patient subpopulations, that is, children, pregnant women, and breastfeeding mothers. Prescribing information should be checked before using topical treatments for them (see Supplementary Table S2 for further guidance).

Figure 1 is provided as guidance to aid treatment decision making. It highlights stepwise-treatment decision drivers based on disease location, severity and symptoms, and other considerations, such as presence of itch or patient subpopulations. Disease severity is generally assessed using: Physician Global Assessment (PGA); Body Surface Area (BSA); or Psoriasis Area and Severity Index (PASI), which rate the quality (redness, thickness, and scaliness) and/or surface area of the plaques. For practical tips on estimating BSA see Supplementary Table S2, section 1. Potent and super-potent 
Table 4 Appropriate topical treatments for psoriasis by site and expected time to treatment outcome

\begin{tabular}{|c|c|c|}
\hline Site of psoriasis & Treatment $^{a}$ & $\begin{array}{l}\text { Expected time frame to out- } \\
\text { come }\end{array}$ \\
\hline Body & $\begin{array}{l}\text { - Vitamin D analogues (dose } \\
\text { should not exceed } 5 \text { mg per } \\
\text { week) }{ }^{30,31} \\
\text { - Combination vitamin D analogue } \\
\text { and corticosteroid } \\
\text { - Potent or super-potent } \\
\text { corticosteroids (short-term use } \\
\text { only) } \\
\text { - Salicylic acid plus corticosteroid }\end{array}$ & 2-4 weeks \\
\hline Hands and feet & 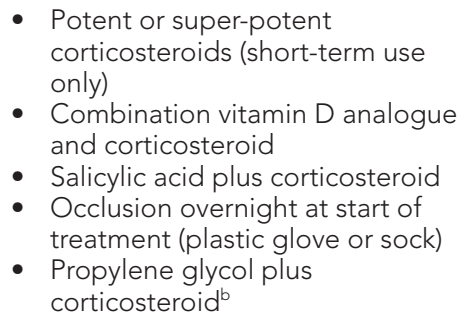 & 4 weeks \\
\hline Scalp & $\begin{array}{l}\text { - Potent or super-potent } \\
\text { corticosteroid } \\
\text { - Combination vitamin D analogue } \\
\text { and corticosteroid } \\
\text { - Salicylic acid plus corticosteroid } \\
\text { - Tar plus salicylic acid plus sulphur }\end{array}$ & 4 weeks \\
\hline Face & $\begin{array}{l}\text { - Low- or mid-potency } \\
\text { corticosteroid } \\
\text { - Topical calcineurin inhibitor }\end{array}$ & 2 weeks \\
\hline $\begin{array}{l}\text { Perianal or genital area and skin folds } \\
\text { (axillae, inframammary, or inguinal } \\
\text { region) }\end{array}$ & $\begin{array}{l}\text { - Low- or mid-potency } \\
\text { corticosteroid } \\
\text { - Topical calcineurin inhibitor }\end{array}$ & 2 weeks \\
\hline
\end{tabular}

This information is based on the expert opinion and clinical experience of the authors and provides a suggested option for a given clinical scenario to contribute to an informed decision; it does not advise that a given treatment is warranted. ${ }^{a}$ Treatments are not listed in any particular order. ${ }^{b}$ Certain countries only (for example, UK and Switzerland). "2-3 days of corticosteroids before switching to topical calcineurin inhibitors (owing to burning).

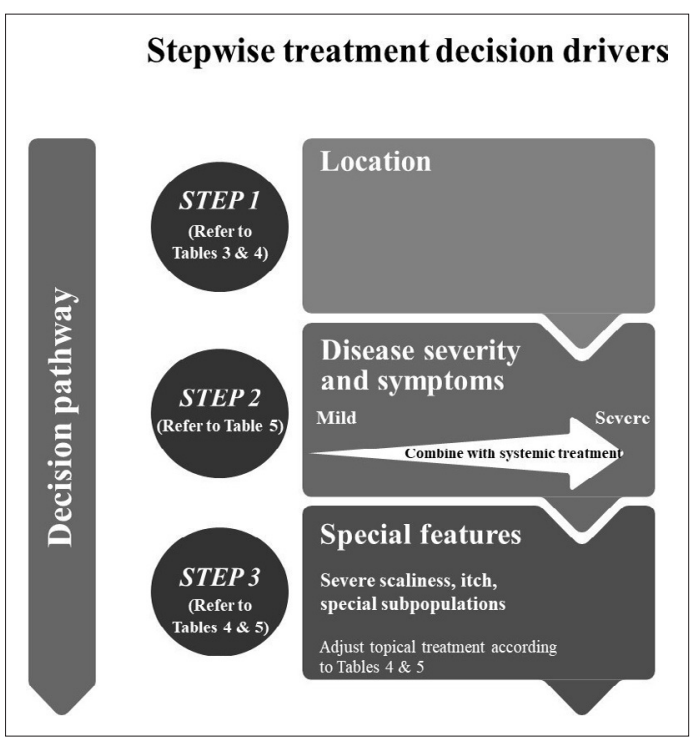

Figure 1 Topical treatment algorithm topical corticosteroids are effective, but their long-term use is limited by concerns about side effects. ${ }^{1}$ For patients receiving topical corticosteroids, particularly the highest potency, it is recommended that disease severity is monitored and an alternative topical treatment is switched to (for example, calcipotriene plus betamethasone dipropionate [Cal/BD] fixed-dose combination) after 2 weeks (if no response) and a maximum of 4 weeks. Calcipotriol and calcipotriol or Cal/BD are marketed by LEO Pharma, the sponsor of this work, under the tradenames (UK) Dovonex (calcipotriol ointment), Enstilar (Cal/BD foam), and Dovobet (Cal/BD gel and ointment). The fixed-dose Cal/BD aerosol foam is preferable because it leads to higher skin penetration of the active ingredients and has superior efficacy compared with ointment or gel formulation ${ }^{15,16}$ and monotherapies. ${ }^{4}$

Emollients play a basic role in the topical treatment of psoriasis, ${ }^{17}$ and there is some 
Table 5 Clinical effectiveness of topical treatments on psoriasis symptoms

\begin{tabular}{|c|c|c|c|c|c|c|c|}
\hline $\begin{array}{l}\text { Key feature of } \\
\text { psoriasis }\end{array}$ & Corticosteroid & Vitamin D analogue & $\begin{array}{l}\text { Cal/BD foam fixed-dose } \\
\text { combination }^{\text {a }}\end{array}$ & Topical calcineurin inhibitor & Salicylic acid & Urea & $\operatorname{Tar}^{\mathrm{b}}$ \\
\hline Redness & +++ & $+/++$ & +++ & $+/++^{c}$ & 0 & 0 & + \\
\hline Scaling & + & $+/++^{d}$ & ++ & 0 & +++ & ++ & + \\
\hline $\begin{array}{l}\text { Thickness or } \\
\text { infiltration }\end{array}$ & ++ & $+/++$ & +++ & + & 0 & 0 & ++ \\
\hline Itching & $++/+++$ & 0 & +++ & ++ & 0 & + & ++ \\
\hline
\end{tabular}

Symbols represent clinical effectiveness, where $+=$ somewhat effective and $+++=$ very effective; 0 represents no or minimal impact on the symptom. This information is based on the expert opinion and clinical experience of the authors and provides a suggested option for a given clinical scenario to contribute to an informed decision; it does not advise that a given treatment is warranted. Only the most commonly used vehicles are included in the Table. It is not intended as a comprehensive list. Clinical effectiveness is based on the active ingredients; overall effectiveness in the real world is also driven by patient adherence and the vehicle plays an important part in patient behaviour. ${ }^{\mathrm{a}} \mathrm{Cal} / \mathrm{BD}$ is marketed by LEO Pharma, the sponsor of this work, under the tradenames (UK) Enstilar (Cal/BD foam) and Dovobet (Cal/BD gel and ointment). 'Use of tar is country-specific: coal-tar preparations are used in the UK ${ }^{32}$ and elsewhere as part of the Goeckermann regimen ${ }^{33}$; however, tar is rarely used in Switzerland, Austria, or Scandinavia. ${ }^{c}++=$ when used on face. ${ }^{\mathrm{d}}$ Cream $=+$; ointment $=++$.

evidence of improvement of psoriasis with keratolytic compounds used as monotherapy or in combination with other therapies, either during or before the use of active drugs. ${ }^{18}$

It is believed there is currently no 'one-size-fits-all' treatment pathway for patients with mild-tomoderate psoriasis and no preferred sequence of treatments. While treatment decision making should be individualised to the patient, choice of treatment and formulation can be based on an individual's key symptom(s). Table 5 has been designed to support treatment decision making based on symptoms of psoriasis and should be used in conjunction with Tables 3 and 4 to factor in the location of the disease.

\section{Optimal outcomes of topical treatment}

Question 3: What outcomes should a physician or patient expect from topical treatment and within what time frame?

a. Satisfactory improvement (for example, changes in redness, scaling, thickness or plaques, and the size of the area involved) should be observed by the patient within 2 weeks. For some symptoms, such as itch, improvement may be felt as early as a few days. ${ }^{19,20} \mathrm{At}$ around 4 weeks, a marked improvement (for example, clear or almost clear outcome) should be expected, even if further improvement can still be seen after 4 weeks. If there is no clinically relevant improvement after 4 weeks, adherence should be assessed (including consumption) and treatment switched if the patient is fully adherent (Table 4).

- If residual redness is seen, without plaque elevation or desquamation, treatment can be tapered.

b. Patient expectations should be carefully managed to ensure they are realistic about:

- how well the medication may work;

- how soon they should expect to see an improvement in symptoms;

- side effects that may occur; and

- any additional treatment that may be required beyond 4-8 weeks.

\section{Topical treatment duration}

\section{Question 4: How long should topical treatments be used for?}

Table 4 details the suggested length of treatment based on the expected time frame to achieving outcome (from expert experience).

a. A topical treatment should be used (except potent and super-potent corticosteroids) at the minimum effective frequency for as long as it provides continuous improvement or disease control, and is safe and well tolerated with minimal side effects.

b. Regardless of plaque location, potent corticosteroids should not be used for longer than 6 weeks without interruption. If remission is not achieved in this time frame, the patient 
should be referred to a dermatologist, as the diagnosis may need to be reconsidered and/ or systemic treatment options considered. In the meantime, less potent corticosteroids or alternative topical drugs can be used. If necessary, after an interruption of at least 6-8 weeks, treatment with potent corticosteroids can be recommenced. This statement is based on clinical experience of dermatologists, as there is no published consistent clinical and experimental evidence to support this statement; the potency of different corticosteroids is provided in Supplementary Table S3.

c. Super-potent steroids, such as clobetasol, should not be used daily for $>2$ weeks.

d. Combination therapies containing topical corticosteroids and salicylic acid (if not contraindicated) can be used for as long as the strength of the corticosteroid component allows, provided that scaling has been significantly reduced.

e. If long-term topical treatment of psoriasis is required, vitamin D3 analogues and their combinations are recommended.

f. Psoriasis should be treated to minimum disease activity regardless of the site of the disease.

The frequency of flares, if ascertainable, can be used to inform whether a patient requires longterm management with topicals. There are different approaches to treatment regimens; for example, option one: used daily for a number of weeks until clear or almost clear and then switched to 'as needed', during which time the patient can retreat when needed. Option 2: treated daily for a number of weeks, followed by gradual tapering; for example, every second day for 2 weeks, then twice a week for 2 weeks, once a week for 2 weeks, and then the treatment is paused. If, however, mild psoriasis activity increases at any stage, tapering should be ceased and an appropriate interval should be established at which the disease is at an acceptable level of activity.

In addition to the 'as needed' and 'tapering' approaches detailed above, maintenance treatment with topical therapies, using reduced potency and/or frequency, can be considered. For example, consider the option of applying topical therapies on two specified days of the week, as agreed in collaboration with the patient.

\section{Drivers of treatment switching, escalation, or sequencing}

\section{Question 5: What are the drivers of treatment switching?}

a. Consider switching topical treatments if:

- poor or no improvement is seen within 4 weeks;

- patient is dissatisfied and wishes to explore other options;

- patient has continued psoriasis-related impairment of HRQoL;

- the treatment is poorly tolerated;

- patient's lifestyle or circumstances change; and/or

- newer interventions with better benefit or risk profiles become available.

b. If poor adherence is suspected and ascertained, the patient should be worked with to try to improve it before switching, unless a treatment-specific factor is the reason for poor adherence.

\section{Drivers of adherence}

\section{Question 6: What features of a topical treatment maximise adherence?}

a. The following features of a topical treatment maximise adherence (Table 1 and Table 2):

- Clinical effectiveness

- The appearance of plaques should be examined to assess disease severity, which is defined as severe (thick and scaly with a lot of erythema), moderate (moderate in its scaling, thickness, and redness), mild or almost clear (possibly still pink and barely perceptible without real scaling), and clear (completely clear without any erythema), as well as improvement in other symptoms, such as itching. ${ }^{7}$

- Fast onset of action 
- Tell the patient that the effect can be expected within 1-2 weeks of treatment and that they must remain patient if it takes longer (that is, up to 6-8 weeks of treatment).

- Tolerable side effects

- Treatments that minimise tolerability problems (for example, burning and itching) and do not cause obvious skin atrophy are preferred.

- Cosmetically acceptable

- Formulation, areas of application, and patient preference should be considered (Table 2).

- Practicability

- Some patients may prefer the simplicity and practicability of a fixed-dose combination regimen, which allows reduced frequency of application versus monotherapies.

- Choose an easy treatment regimen that is also preferred by the patient, for example, once-daily application.

Corticosteroids (alone or in combination) are often the topical treatment of choice, but 'corticosteroid-phobia', which has been described as an irrational fear towards steroids, is a contributing factor in treatment non-adherence. ${ }^{21}$ Rather than prescribe other (often less effective) steroid-free treatments, patients should be reassured that the safety of modern topical corticosteroids is well established when used appropriately. ${ }^{21}$

\section{Topical treatment initiation}

Question 7: What simple instructions can be shared with patients regarding the use of topical treatments to maximise efficacy and adherence?

a. Ensure you have been as specific as possible. Written instruction should contain: name of product, dosing, frequency, body location, and length of treatment.

b. Available written instructions should be used, for example, a compact pocket card, from patient associations or other trusted sources, which you have reviewed and are in line with your recommendations.

c. Where appropriate, family members should be involved to support the patient with their treatment. This is particularly relevant if the disease is located on the scalp or back, or if the patient has reduced mobility or severe obesity.

For further guidance on optimising doctor-patient communication, see Supplementary Table S4.

\section{Considerations beyond topical treatments}

Patients with moderate-to-severe psoriasis should be referred to specialists, as they may require systemic therapy or phototherapy. The experts agreed that patients should remain on topical therapies while transitioning to systemics or while waiting for an appointment with a specialist.

\section{Discussion}

\section{Summary}

This expert and evidence-driven consensus programme, which used a modified-Delphi approach, was intended to provide practical recommendations for GPs for the use of topical therapies in psoriasis, with a view to improving treatment decision making and patient outcomes. This could be particularly useful given the absence of updated guidelines on topical treatments for psoriasis.

\section{Strengths and limitations}

The study endeavoured to seek contribution on clinical best practice from a range of countries, and while substantial differences in clinical practice are not anticipated, recommendations may not fully reflect current best practice in all clinical settings around the globe. 


\section{Comparison with existing literature}

The majority of patients with psoriasis suffer from mild-to-moderate disease and most of them do not require systemic therapy ${ }_{i}^{7}$ instead, the mainstay of their treatment is topical therapy and, where clinically relevant, phototherapy. ${ }^{22,23}$ Advantages of topical treatments over biologic or traditional systemic treatments include: wide availability, lower costs, lack of serious safety issues (traditional systemic treatments are often discontinued owing to safety and tolerability concerns): ${ }_{i}^{24}$ as well as the fact that topical agents can empower patients to take control of the psoriatic disease..$^{22,23}$

A key barrier to treatment success of a topical treatment is patient non-adherence. ${ }^{7}$ Healthcare professionals play a pivotal role in instructing and advising their patients to help improve adherence to treatment, ${ }^{7}$ asking questions to ensure the patient's understanding of benefits and the use of topical therapies as prescribed. The relapsing-remitting disease course of psoriasis means that long-term management is often required, with regular follow-up to assess response and make any necessary treatment adjustments. GPs and practice nurses are in key positions to directly influence a patient's perception of psoriasis, and to clearly explain the importance of continuing treatment. ${ }^{7}$ Substantial and ongoing research in topical treatment has led to: improved efficacy by enhancing drug delivery and bioavailability of active ingredients, without compromising safety; enhanced convenience of application; and increased variety of available formulations. ${ }^{4}$ New topical formulations with greater efficacy and more convenient application could lead to better adherence and provide subsequent long-term maintenance of a disease-free state. ${ }^{4}$ Reformulations of well-known active ingredients, for example, calcipotriol or Cal/BD as foam, have been associated with improved clinical outcomes, ${ }^{25}$ improved cosmetic acceptance, better tolerability, and reduced frequency of application.

\section{Implications for practice}

These recommendations, based on evidence and on expert opinion, were designed to aid GPs in optimising and individualising psoriasis treatment, with regards to choice and optimal use of topical agents.

\section{Funding}

This work was sponsored by LEO Pharma, which provided funding for experts to attend a meeting to discuss practical recommendations on the use of topical treatments for psoriasis, and for medical writing assistance. LEO Pharma was not involved in the generation of recommendations.

\section{Ethical approval}

This was not an interventional study and hence no ethical approval was deemed necessary.

\section{Provenance}

Freely submitted; externally peer reviewed.

\section{Acknowledgements}

The authors would like to extend their gratitude to Professor Peter Berg for his participation in the working group as he played a key role in the identification of key questions, literature research, and the development and review of summary statements and clinical recommendations. The following physicians were also involved in the programme, comprising the wider expert group: Kashif Bhatti, UK; Bernadette Blouard, Belgium; Noelle Colin-Chamley, France; Wim de Kort, the Netherlands; Peter Foley, Australia; Stamatis Gregoriou, Greece; Kurt Gebauer, Australia; Bruno Halioua, France; Jose Luis López Estebaranz, Spain; Anna Szponar-Bojda, Poland; Tiago Torres, Portugal; Dagmar Wilsmann-Theis, Germany. The authors thank these experts for their input into the statements and recommendations, and in helping them to evolve the article into the final output presented here. Medical writing support (including publication planning and scientific editorial services) was provided by Leading Edge Medical Communications, Ltd., Loudwater, UK, funded by LEO Pharma A/S.

\section{Competing interests}

Diamant Thaçi has been a consultant and advisor and/or received speaking fees and/or grants and/ or served as an investigator in clinical trials for the following companies: AbbVie, Almirall, Amgen, Bioskin, Boehringer Ingelheim, BMS, Celgene, Dermira, Dignity, Eli Lilly, Galapagos, Galderma, GSK, LEO Pharma, Janssen, MSD, Morphosis, Novartis, Pfizer, Regeneron, Roche, Sandoz, Sanofi and 
UCB. Pablo de la Cueva has been a consultant and advisor and/or received speaking fees and/or grants and/or served as an investigator in clinical trials for the following companies: AbbVie, Almirall, Astellas, Biogen, Boehringer Ingelheim, Celgene, Janssen, LEO Pharma, Eli Lilly, MSD, Novartis, Pfizer, Roche, Sanofi and UCB. Andrew Pink has served as an advisor, steering group member or lectured for: AbbVie, Almirall, LEO Pharma, Eli Lilly, Sanofi, Novartis, La Roche Posay. Ahmad Jalili has been a consultant and advisor and/or received speaking fees and/or grants and/or served as an investigator in clinical trials for the following companies: AbbVie, Amgen, Boehringer Ingelheim, BMS, Celgene, Eli Lilly, GSK, LEO Pharma, Janssen, MSD, Novartis and Sanofi. Siegfried Segaert has been a paid speaker or consultant for: AbbVie, Almirall, Amgen, Biogen, Boehringer Ingelheim, Celgene, Galderma, Glenmark, Janssen, LEO Pharma, Eli Lilly, Merck Serono, MSD, Novartis, Pierre Fabre, Pfizer, Roche, Sun Pharma and UCB. Kasper Hjuler has been a consultant and advisor for the following companies: AbbVie, LEO Pharma, and has received speaking fees from: AbbVie, LEO Pharma, Novartis, Janssen, CSL Behring. Piergiacomo Calzavara-Pinton has served as an advisory board member or lectured for: Galderma, Almirall, LEO Pharma, Sanofi, Meda and AbbVie.

\section{References}

1. Menter A, Korman NJ, Elmets CA, et al. Guidelines of care for the management of psoriasis and psoriatic arthritis: section 4. Guidelines of care for the management and treatment of psoriasis with traditional systemic agents. J Am Acad Dermatol 2009; 61(3): 451-485. DOI: https://doi.org/10.1016/j.jaad.2009.03.027

2. Zschocke I, Mrowietz U, Karakasili E, et al. Non-adherence and measures to improve adherence in the topical treatment of psoriasis. J Eur Acad Dermatol Venereol 2014; 28 Suppl 2: 4-9. DOI: https://doi.org/10.1111/jdv. 12445

3. Kontochristopoulos G, Kouris A, Chantzaras A, et al. Improvement of health-related quality of life and adherence to treatment with calcipotriol-betamethasone dipropionate gel in patients with psoriasis vulgaris. An Bras Dermatol 2016; 91(2): 160-166. DOI: https://doi.org/10.1590/abd1806-4841.20164476

4. Segaert S, Shear $\mathrm{NH}$, Chiricozzi A, et al. Optimizing anti-inflammatory and immunomodulatory effects of corticosteroid and vitamin D analogue fixed-dose combination therapy. Dermatol Ther 2017; 7(3): 265-279. DOI: https://doi.org/10.1007/s13555-017-0196-z

5. Nast A, Boehncke W-H, Mrowietz U, et al. S3-guidelines for the treatment of psoriasis vulgaris update 2011 (English version). Update. J Dtsch Dermatol Ges 2011; 9 Suppl 2: S1-S95. DOI: https://doi.org/10.1111/j.16100379.2011.07680.supp.x

6. Nelson PA, Barker Z, Griffiths CEM, et al. 'On the surface': a qualitative study of GPs' and patients' perspectives on psoriasis. BMC Fam Pract 2013; 14: 158. DOI: https://doi.org/10.1186/1471-2296-14-158

7. Stein Gold LF. Topical therapies for psoriasis: improving management strategies and patient adherence. Semin Cutan Med Surg 2016; 35(2 Suppl 2): S36-S44. DOI: https://doi.org/10.12788/j.sder.2016.006

8. Reich K, Zschocke I, Bachelez H, et al. A topical treatment optimization programme (TTOP) improves clinical outcome for calcipotriol/betamethasone gel in psoriasis: results of a 64-week multinational randomized phase IV study in 1790 patients (PSO-TOP). Br J Dermatol 2017; 177(1): 197-205. DOI: https://doi.org/10.1111/bjd.15466

9. Storm A, Benfeldt E, Andersen SE, et al. A prospective study of patient adherence to topical treatments: $95 \%$ of patients underdose. J Am Acad Dermatol 2008; 59(6): 975-980. DOI: https://doi.org/10.1016/j.jaad.2008.07.039

10. International Psoriasis Council. Treatment guidelines; https://www.psoriasiscouncil.org/other_resources_guidelines. htm (accessed 29 Oct 2020).

11. Nast A, Spuls PI, van der Kraaij G, et al. European S3-Guideline on the systemic treatment of psoriasis vulgaris Update Apremilast and Secukinumab - EDF in cooperation with EADV and IPC. J Eur Acad Dermatol Venereol 2017; 31(12): 1951-1963. DOI: https://doi.org/10.1111/jdv.14454

12. Smith CH, Jabbar-Lopez ZK, Yiu ZZ, et al. British Association of Dermatologists guidelines for biologic therapy for psoriasis 2017. Br J Dermatol 2017; 177(3): 628-636. DOI: https://doi.org/10.1111/bjd.15665

13. Menter A, Strober BE, Kaplan DH, et al. Joint AAD-NPF guidelines of care for the management and treatment of psoriasis with biologics. J Am Acad Dermatol 2019; 80(4): 1029-1072. DOI: https://doi.org/10.1016/j.jaad.2018.11. 057

14. Oxford Centre for Evidence Based Medicine. Oxford Centre for Evidence-based Medicine: levels of evidence. 2009; https://www.cebm.net/2009/06/oxford-centre-evidence-based-medicine-levels-evidence-march-2009 (accessed 29 Oct 2020).

15. Paul C, Stein Gold L, Cambazard F, et al. Calcipotriol plus betamethasone dipropionate aerosol foam provides superior efficacy vs. gel in patients with psoriasis vulgaris: randomized, controlled PSO-ABLE study. J Eur Acad Dermatol Venereol 2017; 31(1): 119-126. DOI: https://doi.org/10.1111/jdv.13859

16. Koo J, Tyring S, Werschler WP, et al. Superior efficacy of calcipotriene and betamethasone dipropionate aerosol foam versus ointment in patients with psoriasis vulgaris - a randomized phase II study. J Dermatolog Treat 2016; 27(2): 120-127. DOI: https://doi.org/10.3109/09546634.2015.1083935

17. Thaçi $D$, Augustin M, Krutmann J, et al. Importance of basic therapy in psoriasis. J Dtsch Dermatol Ges 2015; 13(5): 415-418. DOI: https://doi.org/10.1111/ddg.12615 
18. Jacobi A, Mayer A, Augustin M. Keratolytics and emollients and their role in the therapy of psoriasis: a systematic review. Dermatol Ther 2015; 5(1): 1-18. DOI: https://doi.org/10.1007/s13555-015-0068-3

19. Leonardi C, Bagel J, Yamauchi P, et al. Efficacy and safety of calcipotriene plus betamethasone dipropionate aerosol foam in patients with psoriasis vulgaris - a randomized phase III study (PSO-FAST). J Drugs Dermatol 2015; 14(12): 1468-1477.

20. Jalili A, Lebwohl M, Stein Gold L, et al. Itch relief in patients with psoriasis: effectiveness of calcipotriol plus betamethasone dipropionate foam. J Eur Acad Dermatol Venereol 2019; 33(4): 709-717. DOI: https://doi.org/10. $1111 /$ jdv. 15393

21. Belloni Fortina A, Neri L. Topical steroids and corticophobia. G Ital Dermatol Venereol 2013; 148(6): 651-654.

22. Girolomoni G, Calzavara Pinton $P$, Cristaudo A, et al. Back to the future: a new topical approach for mild-tomoderate psoriasis. G Ital Dermatol Venereol 2018; 153(3): 375-382. DOI: https://doi.org/10.23736/S0392-0488. 16.05516-4

23. Calzavara-Pinton P, Zanca A, Arisi M, et al. Prevalence of phototherapy in the age of biologics. Dermatology 2018; 234(5-6): 166-172. DOI: https://doi.org/10.1159/000491782

24. Lebwohl MG, Bachelez $\mathrm{H}$, Barker J, et al. Patient perspectives in the management of psoriasis: results from the population-based multinational assessment of psoriasis and psoriatic arthritis survey. J Am Acad Dermatol 2014; 70(5): 871-881. DOI: https://doi.org/10.1016/j.jaad.2013.12.018

25. Iversen L, Dauden E, Segaert S, et al. Reformulations of well-known active ingredients in the topical treatment of psoriasis vulgaris can improve clinical outcomes for patients. J Eur Acad Dermatol Venereol 2017; 31(8): 12711284. DOI: https://doi.org/10.1111/jdv.14277

26. Wiedersberg S, Leopold CS, Guy RH. Bioavailability and bioequivalence of topical glucocorticoids. Eur J Pharm Biopharm 2008; 68(3): 453-466. DOI: https://doi.org/10.1016/j.ejpb.2007.08.007

27. Buhse L, Kolinski R, Westenberger B, et al. Topical drug classification. Int J Pharm 2005; 295(1-2): 101-112. DOI: https://doi.org/10.1016/j.ijpharm.2005.01.032

28. Feldman SR, Housman TS. Patients' vehicle preference for corticosteroid treatments of scalp psoriasis. Am J Clin Dermatol 2003; 4(4): 221-224. DOI: https://doi.org/10.2165/00128071-200304040-00001

29. Tamarkin D, Friedman D, Shemer A. Emollient foam in topical drug delivery. Expert Opin Drug Deliv 2006; 3(6): 799-807. DOI: https://doi.org/10.1517/17425247.3.6.799

30. Electronic Medicines Compendium. Dovonex ointment. Summary of product characteristics. 2019; https://www. medicines.org.uk/emc/product/981 (accessed 29 Oct 2020).

31. Electronic Medicines Compendium. Calcipotriol ointment 50 micrograms $/ \mathrm{g}$. Summary of product characteristics. 2019; https://www.medicines.org.uk/emc/product/6899/smpc (accessed 29 Oct 2020).

32. National Institute for Health and Care Excellence. Psoriasis assessment and management. London: NICE; 2017. https://www.nice.org.uk/Guidance/CG153 (accessed 29 Oct 2020).

33. Fiala Z, Borska L, Pastorkova A, et al. Genotoxic effect of Goeckerman regimen of psoriasis. Arch Dermatol Res 2006; 298(5): 243-251. DOI: https://doi.org/10.1007/s00403-006-0691-z 